
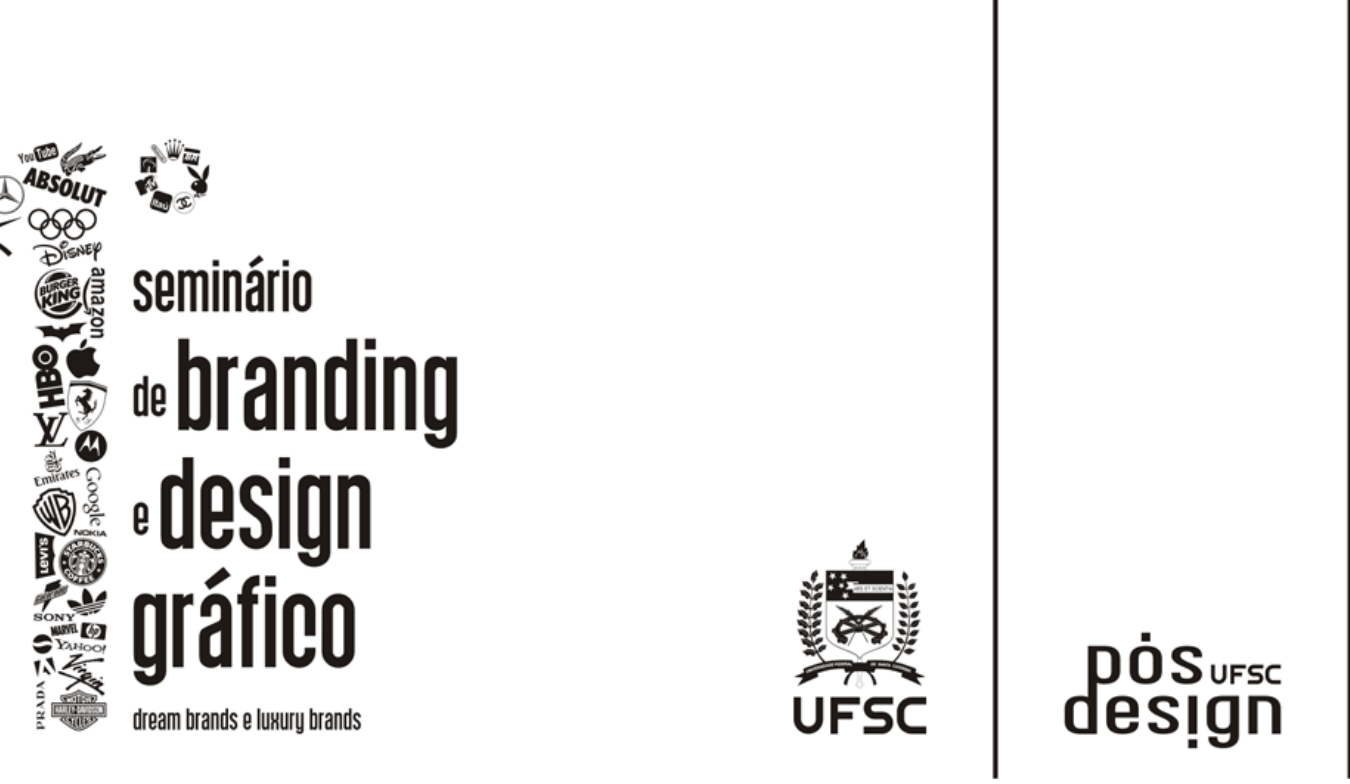

LOGO

\title{
Marcas de luxo: sensação de poder e destaque social
}

Luxury brands: power sensation and social prominence

Neto, Alber; Tecnólogo em Design Gráfico - Cefet-Campos

alber_neto@hotmail.com

Mendonça, Debora; Graduanda em Artes Aplicadas - IUP Arts Appliqués deboraparreiras@hotmail.com

\section{Resumo}

O presente estudo trata de marcas de luxo: características do mercado e de sua influência. São apontadas as peculiaridades do setor em comparação aos demais, e sua estrutura básica (referente ao tamanho das corporações, finanças e tempo de produção). Após é feito uma análise de como as marcas de luxo fazem uso - assim como demais marcas de sucesso - de sua influência cultural ao comercializar seus bens, ou melhor, suas experiências/sensações.

Palavras Chave: Gestão de Marca; Design; Luxo.

\begin{abstract}
The present study deals with luxury brands: market characteristics and its influence. The sector's peculiarities are going to be highlighted compared to others, and its basic structure (corporations size, financial characteristics, and time factor). Afterward, an analysis of how the luxury brands make use-as other success brands - about its cultural influence to sell goods, or better, to sell experiences/sensations.
\end{abstract}

Keywords: Brand Management; Design; Luxury.

O panorama do fim da II Guerra Mundial apontava para os EUA como os grandes vencedores, o que propiciou a disseminação do American Way Of Life na maior parte do mundo ocidental - fator preponderante para que se entenda o modus vivendi dos dias atuais. 
Diferente das décadas passadas onde a Depressão e a Guerra condicionaram a moderação e o racionamento, a população estadunidense durante a década de 1950 era "bombardeada" pelo novo mercado de massa, repleto de produtos inovadores, rápidos e eficazes. O povo deixou para trás os tempos de guerra e impulsionados pelo futuro maravilhoso que a televisão, as revistas e as propagandas mostravam, consumia descontroladamente.

A televisão se torna o pilar do consumo, seduzindo homens, mulheres e crianças por todo EUA. A venda de aparelhos de TV aumentou de 3,1 milhões em 1950 para 32 milhões em 1955. Em 1959 os norte-americanos passavam uma média de 6 horas por dia, 7 dias por semana na frente da "boob tube". (Heimann, 2003)

Além do advento e popularização de novas mídias, havia a invenção, oferta, e popularização de inúmeros produtos. Ainda neste momento, começava-se uma integração maior entre os mercados. Dado o panorama do poder de compra e de possibilidades apresentadas ao público, cita-se Okonkwo (2007): "quando a ícone do design de moda, Coco Chanel, declarou que 'luxo é a necessidade que se dá quando a necessidade acaba', sabia exatamente do que estava falando".

\title{
Diferenciais da indústria do luxo
}

Os principais aspectos que diferenciam o setor de luxo dos demais circundam o tamanho da corporação, finanças e o tempo de produção.

Na maioria dos negócios, o tamanho da corporação é dos mais importantes - se não o mais importante fator usado em nível de comparação. Porém o mesmo não acontece no setor de luxo. No geral, o mercado de luxo é pequeno, mas possui uma reputação que impressiona:

\begin{abstract}
A Dior tem suas receitas anuais em aproximadamente 800 milhões de euros, enquanto o grupo Peugeot tem suas receitas anuais em 56 bilhões de euros. Então, por esses dados, o grupo Peugeot é 70 vezes maior que a Dior. A GM tem suas cifras por volta de 150 bilhoes de euros, 200 vezes a da Dior. O número de funcionários nesses casos é provavelmente na mesma proporção, se não maior.

[Mas ao se questioner um] consumidor norte-americano, japonês ou chinês para citar um produto ou companhia francesa, a Dior virá primeiro do que a Peugeot. (Chevalier e Mazzalovo, 2008)
\end{abstract}

Pode-se dizer que, mundialmente, a Dior tem apelo maior do que a Peugeot. Este apelo é explicado pelo fato de os consumidores terem um grande interesse em marcas de luxo e de moda. "Moda não se trata apenas de roupas e acessórios, mas de uma forte influência cultural na sociedade, atribuí certa identidade e estilo de vida" (Okonkwo, 2007). Porém, apesar de terem uma imagem de prestígio e campanhas publicitárias por todo mundo, corporações de luxo são de porte pequeno a médio (com exceções de conglomerados de marcas, como o LVMH).

Mesmo dentro do setor de luxo é difícil comprar as diversas marcas. Diferentemente da Louis Vuitton que possui cerca de 400 lojas espalhadas pelo planeta ou a supracitada Dior, 
algumas corporações são ainda menores e mesmo assim possuem apelo com inúmeros consumidores.

A Carven [, por exemplo,] tem receita anual entre 1 e 2 milhões de euros. [... No entanto,] o fato é que algumas marcas são projetadas a partir de licenças, com royalties de apenas 2-3\% sobre as vendas. Assim explica-se o porquê de algumas marcas de luxo serem tão pequenas e terem presença em várias lojas nos mais diversos países. (Chevalier e Mazzalovo, 2008)

Ainda a respeito das finanças das corporações desse setor, acrescenta-se que um número considerável de marcas obtêm saldos negativos ao em vez de lucros, e mesmo assim são mantidas. Isso se dá pelo valor que essas marcas possuem, por continuarem a gozar do sucesso de outras épocas, e por terem sido tão lucrativas em outros momentos que podem compensar muitos anos de perda. Além disso, marcas de luxo são trunfos que podem vir a ser tornar sinônimo de um estilo de vida, e por sua vez, proporcionar uma extensão de linha de produtos (Chevalier e Mazzalovo, 2008).

Outro fator tange a alta qualidade dos materiais empregados e das técnicas, o que acarretará maior tempo de produção. Serão detalhes como esse que irão separar um relógio da Chanel de um relógio de supermercado. Desta forma a Chanel pode estabelecer um preço especial de três mil dólares, enquanto o relógio do supermercado custará 30 dólares. Ou mesmo a perícia e precisão do trabalho de 18 horas feito a mão por um único trabalhador, do começo ao fim, que farão uma bolsa Hermès Birkin ter o preço de duas passagens de primeira classe de Paris para Nova York, entre tantos outros exemplos (Okonkwo, 2007).

\section{Pontos em comum entre marcas de luxo e demais marcas de sucesso}

(Para essa abordagem foram consideradas marcas de sucesso que têm produtos de fácil acesso ao grande púbico em geral, como refrigerante e café; respectivamente, Coca-cola e Starbucks.)

Certa vez, Andy Warhol, um dos maiores nomes da Pop Art, disse que:

O que tornou a América Fabulosa, foi que estabeleceu uma tradição em que os consumidores ricos compravam basicamente os mesmos produtos que os pobres. Poderíamos ver televisão e beber Coca-Cola sabendo que o presidente bebia Coca-Cola. [...] Uma Coca-Cola é uma Coca-Cola, e nenhuma quantidade de dinheiro no mundo poderia comprar uma melhor. (Honnef, 2004)

Como fora supracitado, marcas de luxo fazem uso de materiais e métodos diferenciados dos demais setores para produção de seus produtos. Porém essa diferenciação material acrescenta, principalmente, qualidades a marca: poder, caráter de exclusividade e inovação, etc. Em outras palavras, alimentam-se os aspectos intangíveis da marca.

Por essa ótica, existem pontos em comum entre refrigerantes (e demais produtos de baixo custo em geral) e peças de luxo. Tom Peters (2004) afirma que "A Harley-Davidson não vende 
motocicletas. A Starbucks não vende café. [...] Pense nisso". Marcas vendem experiências/sensações. A Strabucks (que trabalham com um produto tão simples quanto a CocaCola) vende "Um-Novo-Eu-Pela-Manhã", e a Harley-Davidson vende mais que luxuosas motos, vende "Estilo de Vida Rebelde"; assim como a Louis Vuitton, a Hermès, ou a Chanel vedem mais que vestuário, cosméticos e acessórios.

Volta-se a Warhol. Em 1962, sob diversas criticas a respeito da técnica (dita) mecanizada de suas obras, Warhol executou "80 Two Dollar Bills (Front and Rear)". A tela mostrava, como diz o próprio título, 80 notas de dois dólares (frente e verso). Em suma, não existiam grandes diferenças entre notas originais e as "falsas" impressas através de serigrafia na tela. A real diferença residia em que o valor das notas de dólares da obra ser consideravelmente maior do que as notas simbolizadas. Porém, para saber esse valor seria necessária uma troca comercial. Assim Warhol expôs que "o valor de uma obra de arte não é medido apenas pela sua qualidade estética, o que quer que isso seja, mas também pelo preço que pode impor e, não esquecendo, pelo prestígio de seu autor" (Honnef, 2004).

Da mesma forma, pode-se dizer que por mais valiosos que sejam os materiais e por mais rebuscadas que sejam as técnicas usadas na fabricação de produtos luxo, seus valores são potencializados pela dimensão simbólica e status de cada marca. Estes valores são transmitidos para o público por diversos meios, como ilustra o trecho a seguir:

\footnotetext{
Quando se vira as páginas de uma revista de moda, o quê é visto? Uma variedade de anúncios de luxo, com muitas cores e atraentes fotos de modelos exibindo produtos que dispertam sua atenção e instigam sua sensibilidade. Quando se troca os canais da televisão, se é constantemente bombardeado com notícias de celebridades e reality shows que estimulam o instinto de se sentir atraente, importante e de ser lembrado. Essas pessoas deslumbrantes vistas nas revistas e na televisão falam de forma inconsciente ao consumidor, dizem que seu estilo de vida e bens materiais - como roupas e acessórios também podem fazer o consumidor mais atraente e incluí-lo em um mundo de glamour. Tudo que se precisa é possuir os produtos certos, feitos pelos designers certos. Deve-se almejar um relógio Gucci, uma bolsa Louis Vuitton e óculos Chanel. (Okonkwo, 2007)
}

\section{Considerações finais}

A disseminação do American Way Of Life, a proliferação e oferta de variados produtos, a integração crescente dos mercados, abriram uma lacuna para uma classe com poder aquisitivo maior que buscava produtos com um quê de exclusividade, e impulsiona o mercado de luxo - que ao longo dos anos ganha atenção, inclusive, do público comum.

As campanhas das marcas, como um todo, criam a idéia de que é necessário consumir os produtos anunciados para o sentimento de inclusão na sociedade. Produtos de luxo amplificam essa necessidade. Mais do que o esmero de cada peça, o mercado de luxo lança mão da influência cultural detido pelas grandes marcas, e enfatiza que possuir seus produtos é ter poder social. A experiência/sensação comercializada nesse setor, não se refere apenas à inclusão, mas ao destaque único que se terá perante a sociedade. 


\section{Referências}

CHEVAliER, Michel e MAZZALOVO, Gerald. Luxury Brand Management - A World of Privilege. Nova Jersey, EUA: Wiley, 2008.

HEIMANN, Jim. All-American Ads 50s - Icons Series. Colônia, Alemanha: Taschen, 2003.

HONNEF, Klaus. Pop Art. Colônia, Alemanha: Taschen, 2004.

OKONKWO, Uche. Luxury Fashion Branding - Trends, Tactics, Techniques. Nova York, EUA: Palgrave Macmillan, 2007.

PETERS, Tom. Reimagine! Exelência nos Négocios Numa Era de Desordem. São Paulo: Futura, 2004. 